\title{
THE IMPACT OF HYDROMETEOROLOGICAL EVENTS ON THE STATE OF THE URBAN RIVER QUALITY
}

\author{
WPEYW ZJAWISK HYDROMETEOROLOGICZNYCH \\ NA STAN JAKOŚCIOWY RZEKI MIEJSKIEJ
}

\begin{abstract}
One of the aims of this paper was to study catchment and watercourse response to extreme events. The study area consisted of Orunski Stream in the northern Polish city of Gdansk. The study period (review of cartographic materials) covered the years 1908 to 2000, while field research covered the period from May 2009 to April 2010. In addition, measurements were performed to study the dynamics of changes occurring in the creek during rainfall events. Examination of the water chemistry changes made two days before heavy rainfall showed a significant increase in sulphates and nitrogen compounds. Additionally, pollutants washed from the basin contributed to a significant deterioration in the water colour. A rainfall of $1.3 \mathrm{~mm}$ caused an eleven-fold increase in stream flow, a twofold increase in the water level, and a fourfold increase in the velocity of water molecules. It might appear seem that such a small amount of rainfall would have no major effect on the hydrologic and hydrochemical parameters of a small creek. However, it is the maximum flow rate that is an important variable when assessing potential flood risk levels.
\end{abstract}

Keywords: weather conditions, extreme events, precipitation, water quality, river transportation

\section{Introduction}

The effect of intense urbanisation on the natural environment is one of the most important problems of the modern civilisation. Urban areas significantly alter the hydrologic cycle and affect the quantity and quality of water. Changes in water quality, leading to its limited usefulness, have become a problem for many regions, especially those highly industrialised and urbanised [1]. This is particularly visible in the era of climate change and its implications for the volume and intensity of precipitation, followed by changes in biological and geographical conditions, including the hydrological ones [2]. Do not forget also about the impact on the man himself, which may cause flooding [3] or water deficit [4] in the city area. The need for efficient management of water resources in urban areas is now more urgent than ever, taking into account population growth and increased needs for reliability under the conditions of climate change [5].

\footnotetext{
${ }^{1}$ Department of Hydrology, Faculty of Oceanography and Geography, University of Gdańsk, ul. J. Bażyńskiego 4, 80-309 Gdańsk, Poland, email: pietruszynski@gmail.com

*Corresponding author: georc@univ.gda.pl
} 
Cities, which are the centres of anthropogenic transformation of the natural environment, exert a strong impact on the quantity and quality of the water circulating within their borders [6]. A decisive role here is played by the impact of surface runoff washing away contaminants from the surface of urban areas [7], which then quickly and easily reach the river system via the storm water drainage systems [8]. Urban watercourses are often canalised and included in closed systems, so that the ability of their water to self-purify is very limited. The result is a rapid eutrophication of surface water and the deterioration of its quality.

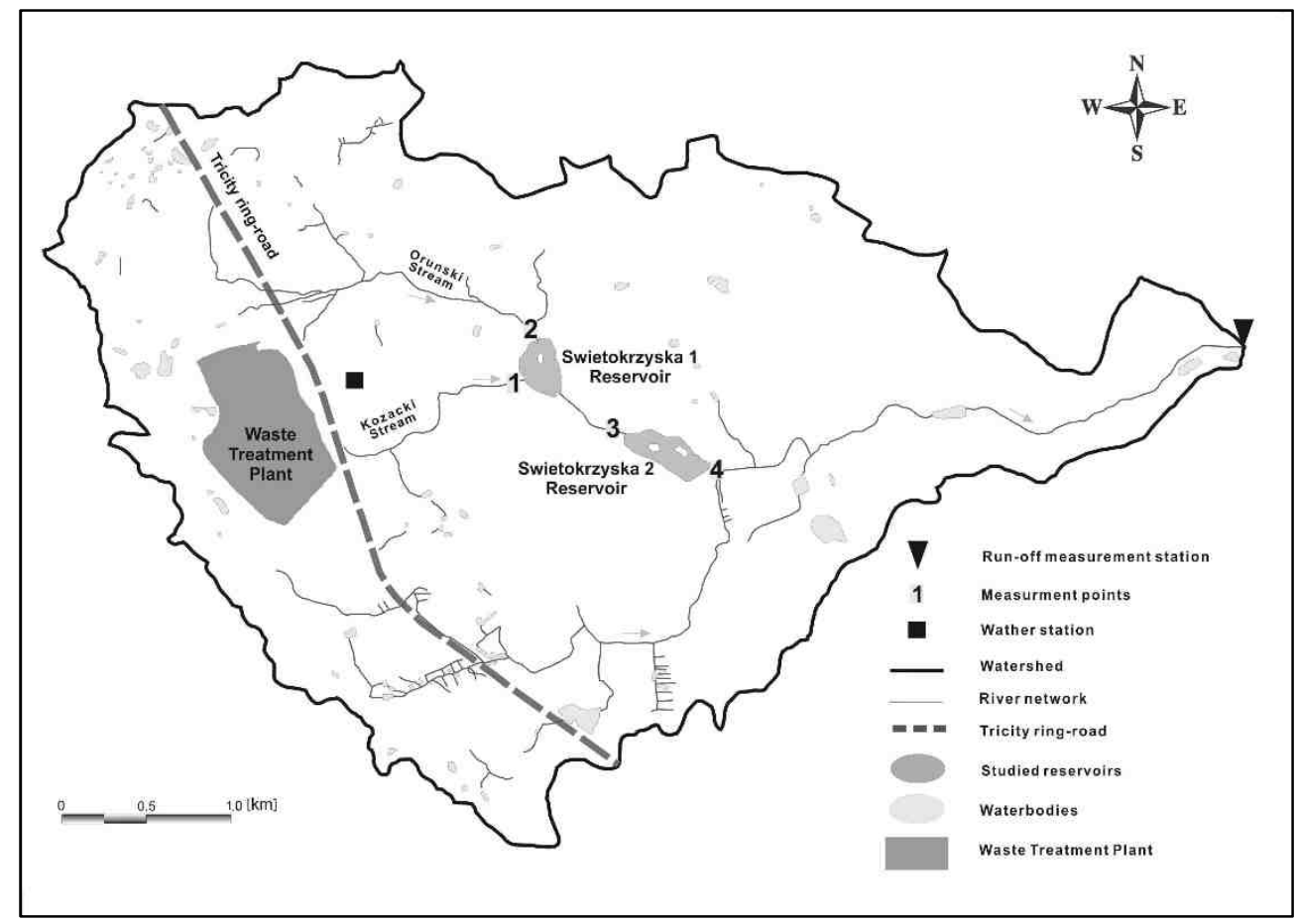

Fig. 1. Hydrography and location of gauging stations in the catchment of the Orunski Stream

Watercourses in urban areas are generally strongly transformed: riverbeds show changed hydromorphic characteristics while water shows changed physical, chemical and biological properties. The outflow within an artificial hydro infrastructure with a forced drainage network is in fact largely dependent on extreme weather conditions [9]. A characteristic feature of such a catchment runoff is rapid reaching maximum flow, which is an almost immediate response to heavy rainfall or rapid thaw [10]. In urban areas, heavy rain flow often brings local or extensive floods, which is well illustrated by the flood which occurred in Gdansk in 2001. As a result of heavy rainfall in July 2001 the Radunia Canal could not take the water flowing from the morainic hills so it breached and flooded the city districts on its right bank. As a result of this rainfall, the flood water of the Siedlecki Stream flooded the train station and main streets of the city. As a result of the overflow of the Srebrzysko Reservoir its main dam breached and one of the major thoroughfares of 
Gdansk, connecting the city to the airport, was flooded [11]. It is therefore important that currently the principles of sustainable development are applied in urban areas so that the civilisation and urbanisation progress does not dominate over the environmental needs of the city [12]. As a consequence, efforts should be made so as not to disturb the conditions of the abiotic environment, as this could cause environmental disasters and extreme events.

The study hypothesized that cities, which are areas of highly anthropogenically changed environment, exert a strong impact on the quantity and quality of water circulating within their borders.

Hydrographic system of the Orunski Stream catchment drains the eastern edge of the Kashubian Lake District and is part of a larger hydrographic unit, i.e. the basin of the Radunia Canal. The catchment of the Orunski Stream occupies $16.5 \mathrm{~km}^{2}$ and is located in the urban area of the Poludnie District, one of the fastest growing districts of Gdansk, with the greatest spatial potential for new housing. What has been observed over the last decade is a highly progressive pressure of the growing city evidenced by a very rapid emergence of new residential areas and large commercial and service companies.

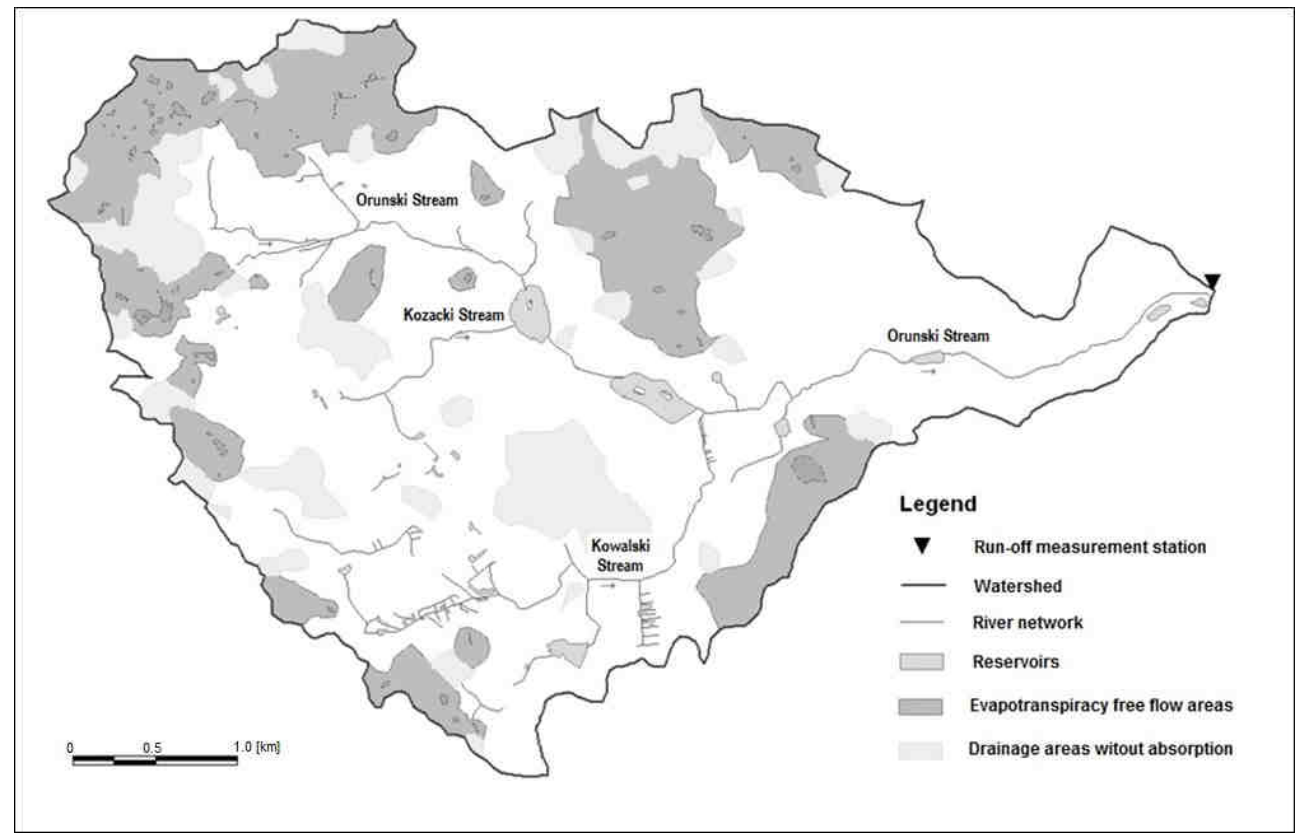

Fig. 2. Hydrographical network of the Orunski Stream

The Orunski Stream is the largest tributary of the Radunia Canal. The Canal and its tributaries create a network of surface drainage taking water from the morainic plateau to the east. The river network of the Orunski Stream is asymmetrical and relatively poorly developed (river network density is $1.58 \mathrm{~km} / \mathrm{km}^{2}$ ). The dominant are the right-bank tributaries. The longest tributaries are: Kowalski Stream $(3.63 \mathrm{~km})$ and Kozacki Stream $(1.49 \mathrm{~km})$. The longest left-bank tributary is the Szadulski Stream $(1.14 \mathrm{~km})$. The length of 
the Orunski Stream is $7.03 \mathrm{~km}$ (Fig. 1). The falls in the catchment range from 0.07 to $2 \%$, and the average fall is $1.47 \%$.

Almost $67 \%$ of the catchment area of the Orunski Stream is actively involved in feeding watercourses, while the rest of the area are endorheic basins not taking part in the surface drainage system. These are mainly endorheic evapotranspiration areas $\left(3.57 \mathrm{~km}^{2}\right)$ which occupy $21.6 \%$ of the catchment area; they account for almost $65 \%$ of all endorheic areas. In contrast, the endorheic absorbent areas $\left(1.93 \mathrm{~km}^{2}\right)$ represent $11.7 \%$ of the analyzed catchment, and $35 \%$ of all endorheic areas (Fig. 2).

After the flood of 9 July 2001 in Gdansk, the hydraulic structures were modernised and the structures on the banks of the Orunski Stream riverbed were improved to better and even the runoff. This was done along a stretch of 1420 meters using fascines to protect the watercourse slope and stone mattresses to protect the slopes at culverts and stone barrages (Fig. 3). Due to a high risk of erosion the mouths of the retention reservoirs were secured by heavy embankments composed of vegetation stone rollers. At the outlet of the water from the storage reservoir Swietokrzyska 2 the riverbed was paved and lined with coco mats and stone mattress. An important aspect was the construction of two retention reservoirs - Swietokrzyska 1 and Swietokrzyska 2 (Fig. 4).

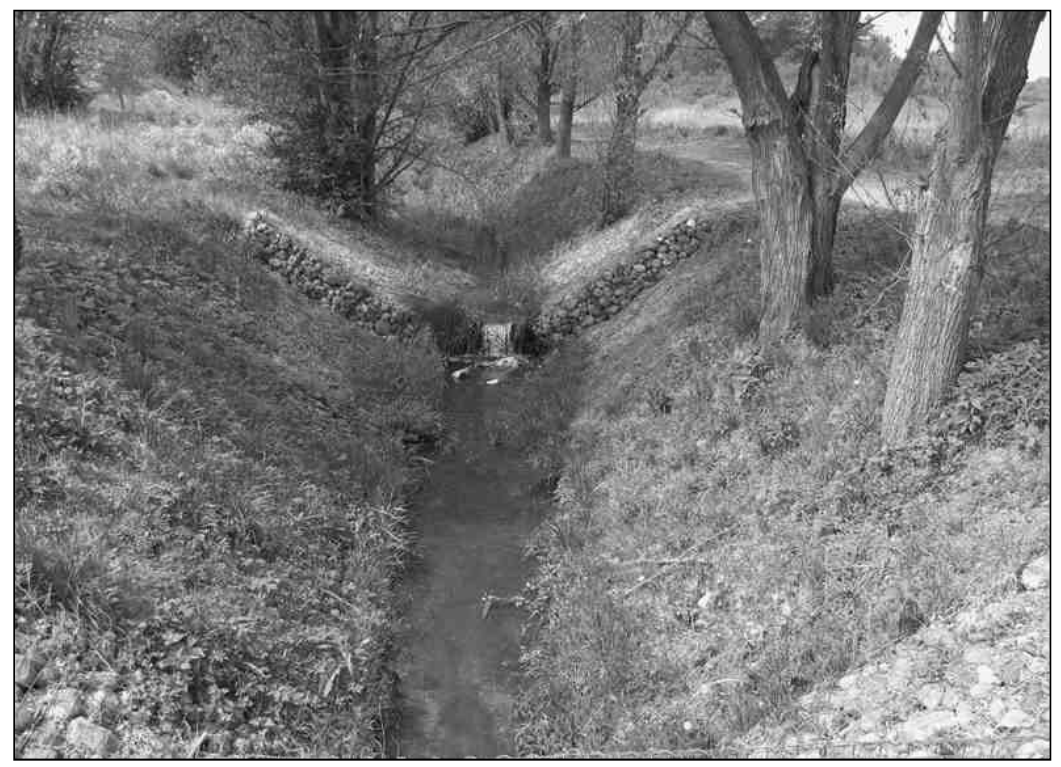

Fig. 3. Orunski Stream - stone water stairs (photo: Ł. Pietruszyński)

One of the rapidly enlarging districts of Gdansk is Poludnie. This district has the greatest spatial potential for new housing. It takes $39.4 \mathrm{~km}^{2}$ (14.8\% of the area of Gdansk) and is inhabited by 67000 people. The areas of urban investment occupy $36.3 \%$ of the district's surface area, farmland $8.6 \%$ and forests $6.3 \%$. Within the limits of the district area surface water occupies $2 \%$ and the number of the existing reservoirs of various origins is 92 . The main natural surface drainage system of the district is the Orunski Stream. 


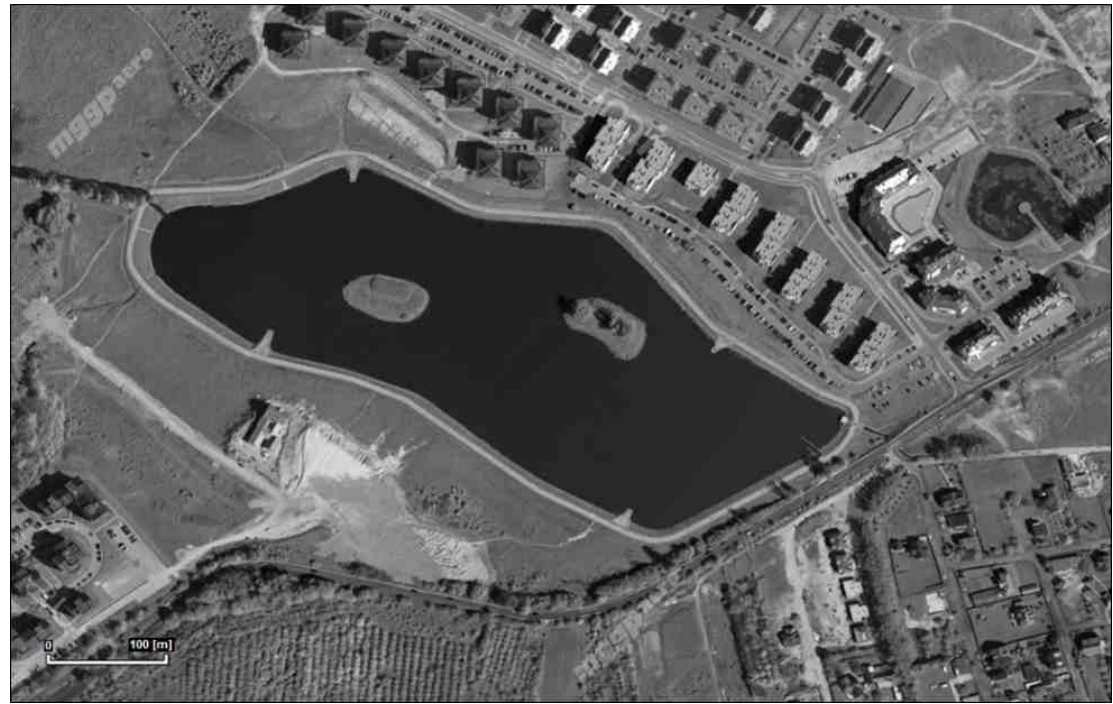

Fig. 4. Aerial photo of retention reservoirs Swietokrzyska 2 (photo: www.zumi.pl)

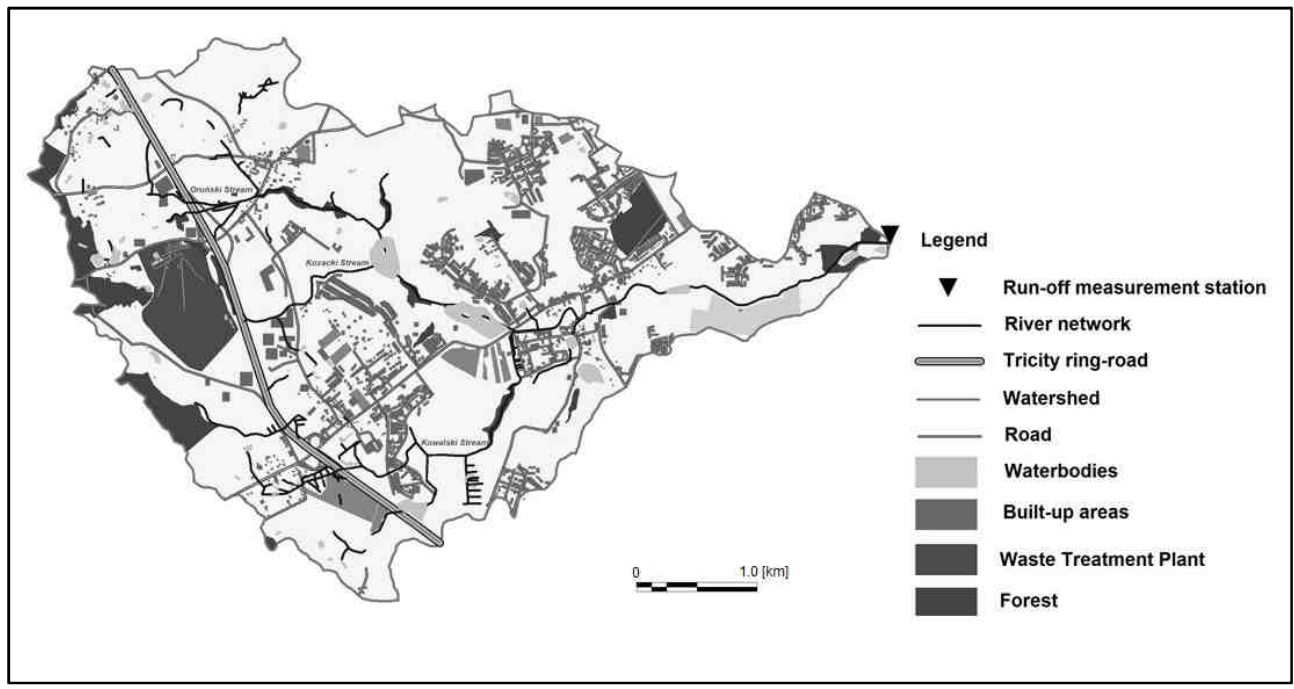

Fig. 5. Anthropopressure in the catchment of the Orunski Stream in 2016

To present the temporal changes taking place in Gdansk, the state of the Orunski Stream catchment in 1908, 2000 and 2016 was compared. At the beginning of the $20^{\text {th }}$ century the settlement network in the area was small: there were several small villages and an insignificant length of the paved roads. The following years saw little change of the settlement network and its negligible impact on the environment. More important events in the study area included the construction of a waste disposal plant with the transformation of the hydrographic network as well as the construction of the Tri-City ring road crossing the 
catchment area. Since 2000, a strong progressive pressure of the Gdansk sprawl can be noted on the north-east side of the city, i.e. a rapid development of new housing estates and large service and industrial companies. In 2016, further development of housing estates was noticed. Also, the development of the flood protection system has been noted. At that time, several retention reservoirs were built (Fig. 5).

\section{Methods}

The analysis of the measurement material was the basis for the evaluation of the influences of urbanisation (landfill, ring road, rainwater collectors) on the water quality of the Orunski Stream in different hydrological seasons, as well as the evaluation of how the brook catchment responds to extreme water supply, i.e. whether after heavy rain a larger amount contaminants and biogenic substance is released to the watercourse.

The changes in the water quality were determined on the basis of a series of measurements of the physical and chemical parameters of the studied watercourses. Water samples for the analysis were collected every month between May 2009 and April 2010. In addition to regular, monthly measurements of physico-chemical properties of water, two additional fieldtrips in the area were conducted in order to investigate the reaction of the brook and its catchment to the rain phenomena. The first visit to the area took place on 12 June 2009. It was preceded by two days of torrential rainfall. Another field visit took place on 31 May 2010. In this case, experimental measurements were conducted to observe the dynamics of changes occurring in the brook during rainfall.

At the same time, other measurements were conducted: the flow of the Orunski Stream and its tributaries as well as the water properties, such as temperature, conductivity, $\mathrm{pH}$ and oxygen saturation, measured in situ.

The $\mathrm{pH}$ measurements were performed using a HatchLange multiparameter meter HQ30D with a gel $\mathrm{pH}$ gel electrode, while the measurement of electrolytic conductivity and water oxygen saturation were performed with a multiparameter meter HQ40D HatchLange with a conductometric vessel and LDO oxygen electrode installed.

Chemical analyses of the water samples collected in the field were performed in the hydrochemical laboratory of the Hydrology Department, Geography Institute of the University of Gdansk. The location of the measurement sites are shown in Figure 1.

The concentrations of total nitrogen, nitrates, nitrites and sulphates were determined with the colorimetric method using the spectrophotometer PhotoLab Spektra by WTW. The measurement of colour was performed using the colorimeter PFXi 195 by Tintometer Lovibond.

During the field work on 31 May 2010 a portable weather station Vantage Pro 2 by DAVIS was installed in the study area to measure the volume of rainfall. In the watercourse a measurement set by Teledyne was installed for recording extreme phenomena. The equipment recorded the following parameters: water level (state), water molecules velocity and flow rate. In addition, water temperature was measured. Additionally, a multiparameter meter YSI Professional Plus was used to measure the basic water parameters, such as dissolved oxygen, electrolytic conductivity, salinity, $\mathrm{pH}$ and water temperature.

The meteorological data were obtained from the automatic station of the Armaag Foundation located within the Orunski Stream catchment area in Szadolki. 


\section{Results}

The annual rainfall in the analyzed year was $479 \mathrm{~mm}$. During the year the highest monthly precipitation was recorded from May to October. The highest average precipitation was recorded in October $(109 \mathrm{~mm})$, while the lowest rainfall was recorded in April $(1.0 \mathrm{~mm})$.

The first study visit, which took place on 12 June 2009, as already mentioned, was preceded by two days of torrential rainfall. On 10 June the average daily total rainfall was $11.2 \mathrm{~mm}$, and on 11 June, the daily rainfall was $18.6 \mathrm{~mm}$. An additional study was to investigate the possible chemical changes in the water.

The laboratory results showed a significant increase in the sulphate concentrations in the water at all gauging sites (Fig. 6). Sulphates are considered as anthropogenic substances which get into the water from eluting sedimentary rocks, soil leaching and oxidation of sulphides and sulphur, which are the products of protein disintegration derived from plants. Rainwater can also be a source of sulphates.

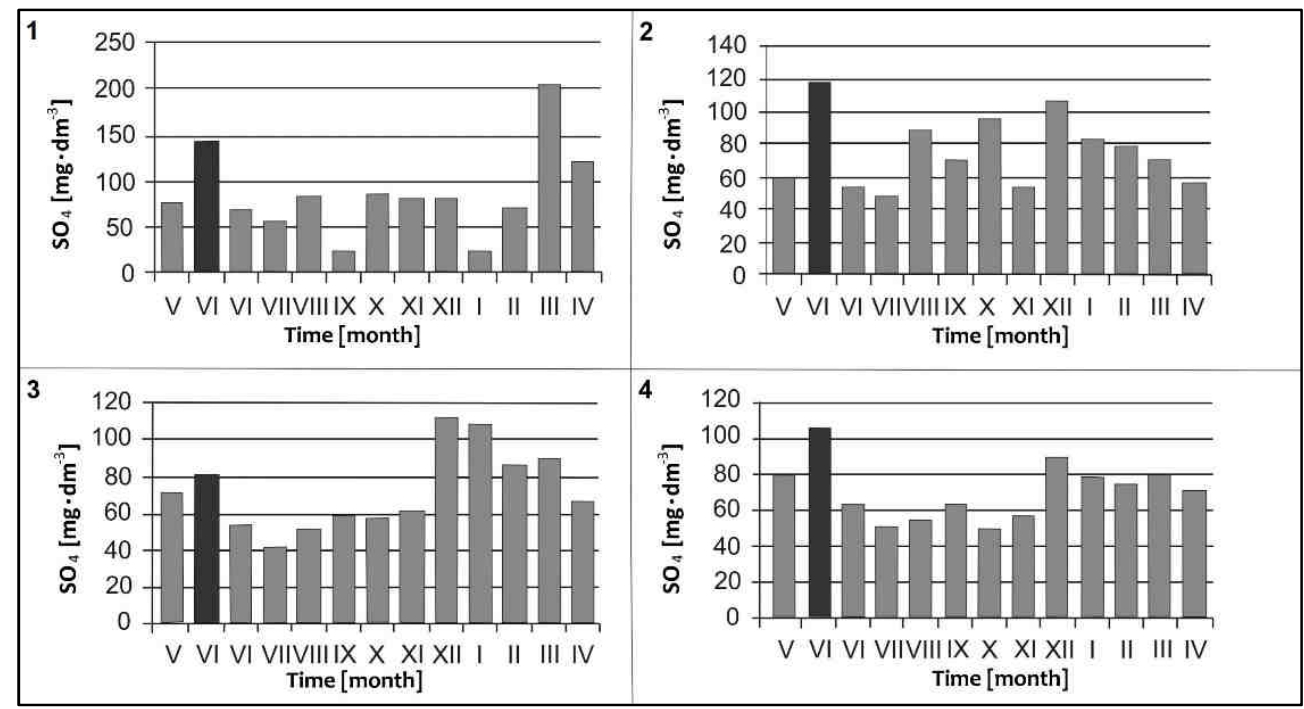

Fig. 6. Seasonal changes in the concentrations of sulphates in the individual measurement and control stations after heavy rainfall (1, 2, 3, 4 measurement points - see Fig. 1)

In the case of the tributaries of the retention reservoir Swietokrzyska 1 (profiles 1 and 2 ), the increase in the concentrations of sulphides was significant, and amounted from 79 to $146 \mathrm{mg} \mathrm{dm}^{-3}$ at the station 1 and from 60 to $119 \mathrm{mg} \mathrm{dm}^{-3}$ at the station 2 . In the measurement profile 3 the increase compared to the measurement of 30 May was insignificant and was 72 to $81 \mathrm{mg} \mathrm{dm}^{-3}$, while in the measurement profile 4 the increase was from 80 to $106 \mathrm{mg} \mathrm{dm}^{-3}$. In the profiles 3 and 4 the accumulation of concentrations in the reservoirs, across which they flew, might have happened.

After substantial rainfall an increase in the nitrogen compounds: nitrites, nitrates and total nitrogen was also marked (Fig. 7). The increase in the concentrations of nitrite and 
nitrate usually indicates water pollution. This may be due to inflow of wastewater containing large amounts of nitrogen compounds.

The highest increase in the concentration of selected forms of nitrogen after rainfall was recorded in the second measurement station. After the rain the concentration of nitrite increased from 0.049 to $0.191 \mathrm{mg} \cdot \mathrm{dm}^{-3}$ (390\%); it was also the highest recorded concentration of nitrite in the entire study period. There was also a very significant increase in the concentration of nitrates at that station, i.e. the change from 2.1 to $7.8 \mathrm{mg} \cdot \mathrm{dm}^{-3}$ (371 \%). Again, it was also the highest recorded value during the entire period of the study. The total nitrogen concentration increased over twofold $(218 \%)$ from 1.06 to $2.31 \mathrm{mg} \cdot \mathrm{dm}^{-3}$.

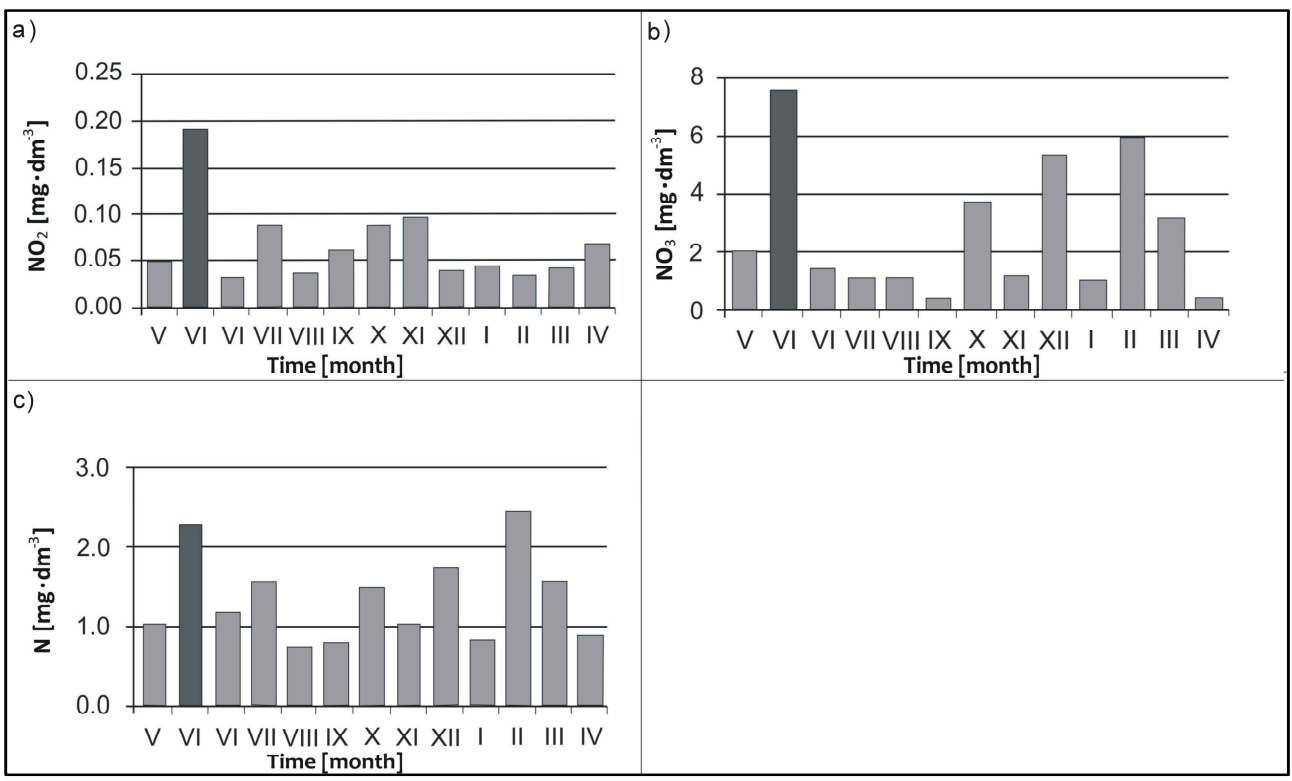

Fig. 7. Seasonal changes in the concentrations of nitrogen compounds at the station 2 after heavy rainfall a) nitrites, b) nitrates, c) total nitrogen

By washing out stable, mineral or organic contaminants from the surface, which later enter the watercourse, heavy rainfall changes the water colour. The supply of contaminants or organic waste (leaves, wood and products derived from their decomposition), contributes to the deterioration of the organoleptic water properties. Such phenomenon is also catchment structure. The colour parameter of the water increased over twofold $(224 \%)$ from 29.9 to $67 \mathrm{mg} \mathrm{Pt} \cdot \mathrm{dm}^{-3}$.

Another study visit took place on 31 May 2010. In that case, the experimental measurements were designed to observe the dynamic changes in the stream during rainfall.

The Kozacki Stream, the main tributary of the Orunski Stream, was selected as a research plot. The measurement site was located at the mouth of the brook to the retention reservoir Swietokrzyska 1. The measurement of the parameters started before the rain, and was continued during and after the rain. The length of the Kozacki Stream is $1.49 \mathrm{~km}$, and the direct watercourse catchment is only $1.03 \mathrm{~km}^{2}$. Based on the collected data and charts, 
which show the variation in the intensity of a given parameter, the following conclusions have been drawn:

- The watercourse reaction to rainfall was immediate. Measurement intervals were set up every 5 minutes. During the very interval in which the rainfall began, a violent reaction of other measured parameters occurred. A correlation can be observed between all the measured hydrological parameters.

- The beginning of the reaction of the examined indicators was at 22:10 when a sharp increase in the measured parameters starts; at the same time, the beginning of the rainfall was recorded $(0.2 \mathrm{~mm})$. A 5-minute delay in relation to the maximum rainfall was noted in the recorded maximum values of the state, flow rate and water velocity.

The first rainfall wave of $1.3 \mathrm{~mm}$ caused a twofold increase in the water level (from the initial state before the rain of 8.5 to $16.5 \mathrm{~cm}$ at the time of the rain culmination), and more importantly, a nearly eleven fold increase in the flow rate from an initial volume of $0.01 \mathrm{~m} \cdot \mathrm{s}^{-1}$ before the rain to $0.106 \mathrm{~m} \cdot \mathrm{s}^{-1}$ immediately after the rain culmination (Fig. 8). Also, the water velocity increased significantly. Before the rainfall the water velocity values ranged between 0.1 and $0.170 \mathrm{~m} \cdot \mathrm{s}^{-1}$, while at the rain culmination it increased to $0.604 \mathrm{~m} \cdot \mathrm{s}^{-1}$ which gives approx. a fourfold increase in the water velocity (Fig. 8). Although the precipitation was measured at the measurement point, it can be assumed that it corresponds to the size of the precipitation in the basin due to its small area.

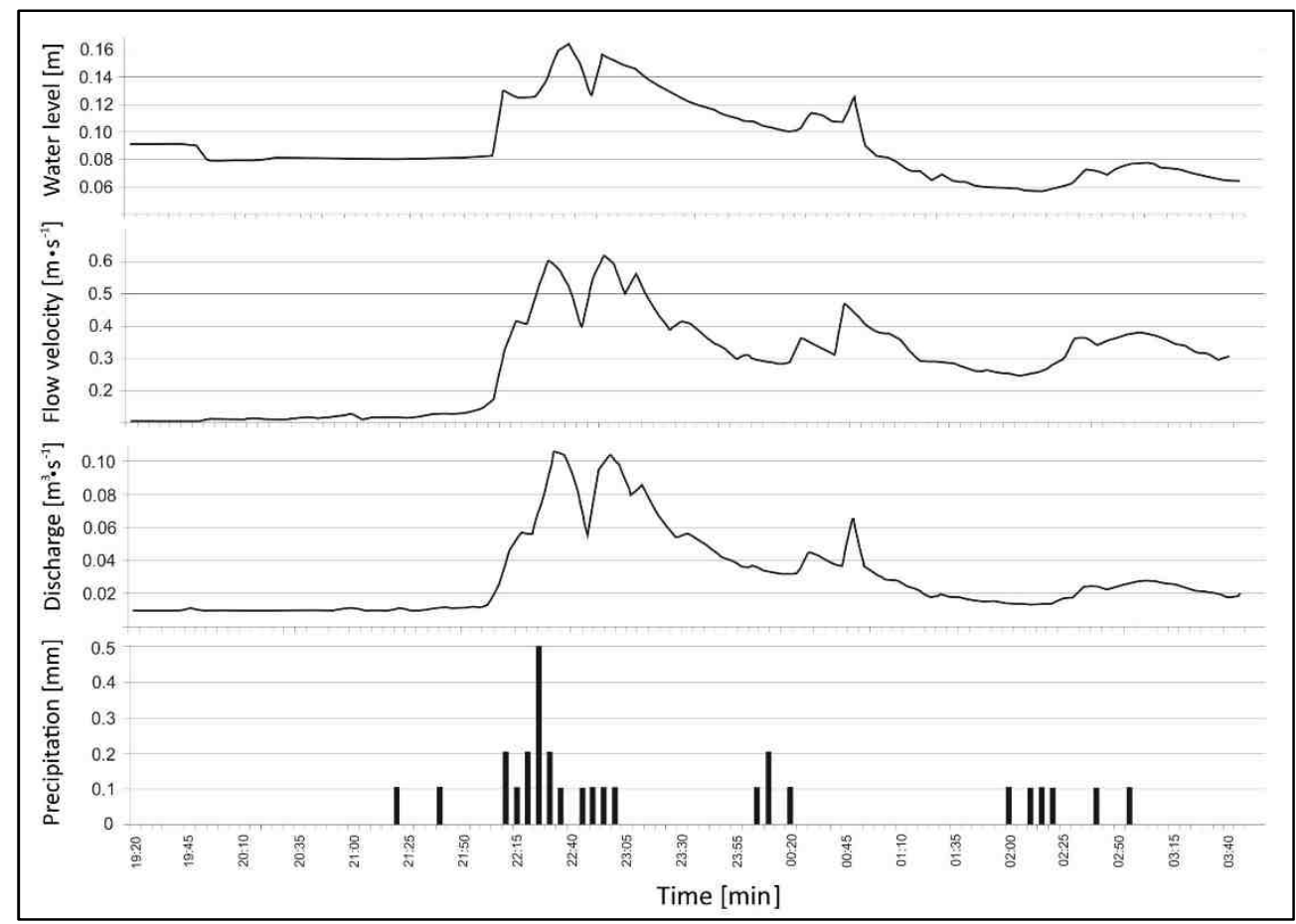

Fig. 8. Temporal variability of hydrological parameters intensity caused by short-term rainfall 
Analysing the results of the variability of the examined physical and chemical properties of water, what can also be observed is the correlation between atmospheric rainfall and other parameters. In the case of these properties, reaction to rainfall was immediate. The sampling interval was set at 3 minutes. After the first wave of rainfall there was a sharp increase in electrolytic conductivity. Before the rain the water conductivity ranged between 427 and $436 \mu \mathrm{S} \cdot \mathrm{cm}^{-1}$. Immediately after the rainfall its twofold increase was recorded, reaching $891 \mu \mathrm{S} \cdot \mathrm{cm}^{-1}$ at the culmination point. Such a rapid conductivity increase was most likely caused by mineral contaminants washed out from the surface by the rain and delivered to the watercourse. At a later stage, a decrease in conductivity down to the value lower than in the initial phase of the study (before rainfall) can be noticed. This is a result of dilution of the water by rainfall. The value of salinity changes in the same way. A twofold increase in salinity was recorded immediately after the rainfall. In the initial phase, prior to the rain, the salinity ranged between $0.23-0.25 \mathrm{ppt}$; immediately after the rain it increased to $0.5 \mathrm{ppt}$. As in the case of conductivity, in a further stage this value decreased to a level lower than in the initial phase of the study (Fig. 9).

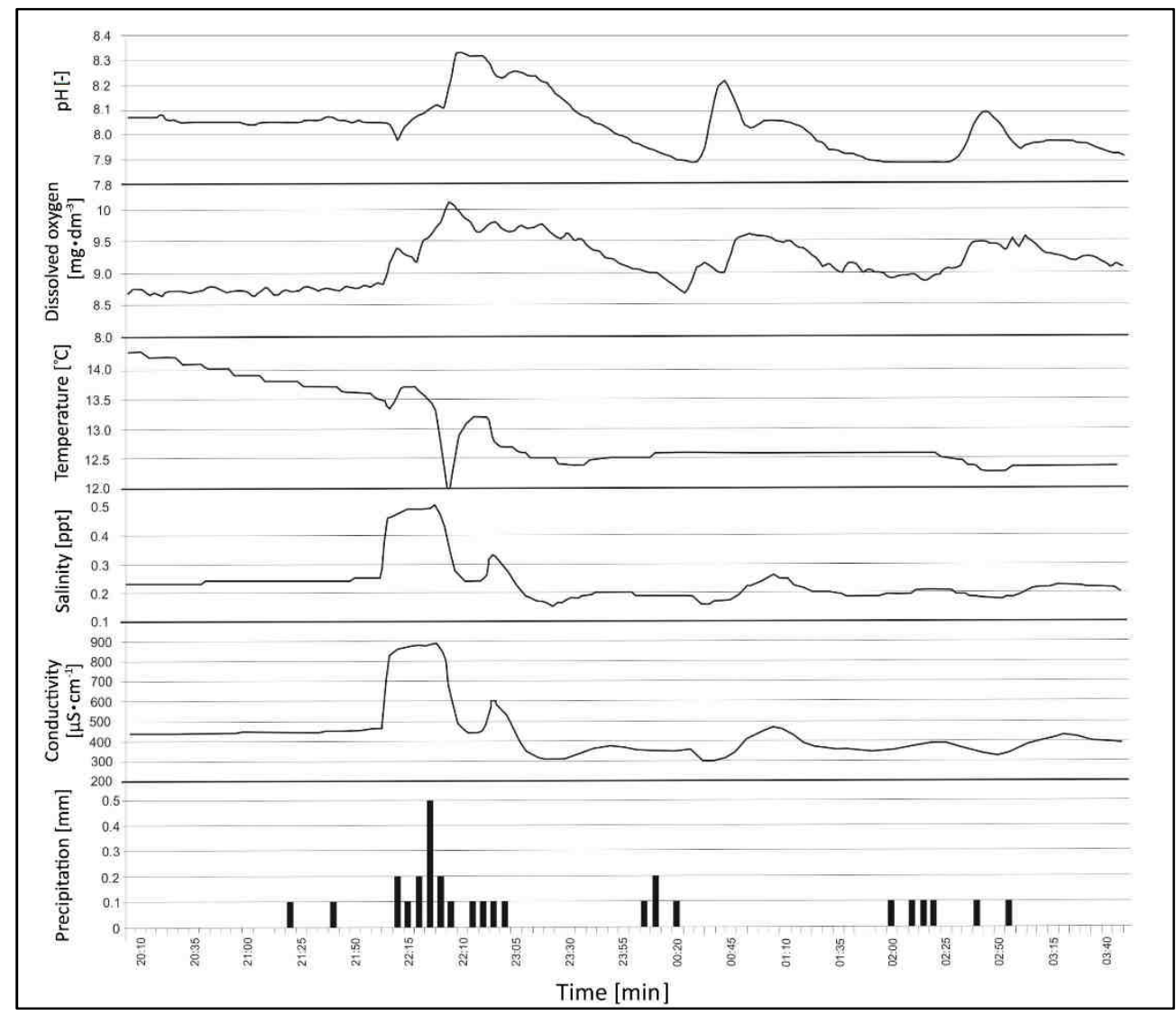

Fig. 9. Temporal variability of hydrological parameters intensity caused by short-term rainfall 
The water temperature graph is also interesting. With the onset of rain, the water temperature rose slightly followed by a rapid decrease by $1.8^{\circ} \mathrm{C}$. The initial temperature rise was most likely caused by slight heating of the atmospheric water by contact with the heated substrate. Next there was a cooling phase of the substrate and the stream was only reached by cooler water from the rainfall. Initially, the delivery of rainfall to the watercourse also resulted in a slight decrease in the water $\mathrm{pH}$. Rainfall usually shows a $\mathrm{pH}$ of 5.7, which is due to the presence of carbonic acid produced by $\mathrm{H}_{2} \mathrm{O}$ reaction with $\mathrm{CO}_{2}$ found in the atmospheric air.

\section{Discussion}

The projected changes in the air temperature and rainfall volume may affect the flow rates of rivers, and thus exert impact on the mobility and dilution of contaminants. In turn, the increase in the water temperature can affect the kinetics of chemical reactions and - in conjunction with poor quality of water their ecological status. Numerous scenarios of climate change suggest an increased incidence of drought during the summer months and a rapid growth of urban floods (flash-floods), which can lead to uncontrolled discharges of pollutants from urban areas to the recipient streams in the area. A good example is the catchment of the Orunski Stream, where in 2001 occurred flood city. Then there has been contamination of large areas of the city Gdansk. The storms a form of extreme phenomena that end periods of drought will cause the outflow of nutrients from urban areas and generate patches of acidification of surface waters [13]. Do not forget about the pollution generated directly by man, even the increase in chloride concentrations in rivers resulting from the salting of roads in winter or through the inflow of industrial or living pollution [14].

Urban watercourses are some kind of poor quality hydraulic systems which quickly respond to external factors, e.g. rainfall; this turns them into potential threats. An example confirming the threat may be the study of Old et al. [15], who performed a study in the entire catchment of strongly urbanised Bradford in West Yorkshire (NE England). Heavy rain which occurred in the centre of Bradford in June 2001 resulted in a sharp increase in the flow rate. In just 15 minutes it increased from 0.45 to $34.6 \mathrm{~m}^{3} \cdot \mathrm{s}^{-1}$, while the volume of suspended matter increased from 14 to $1360 \mathrm{mg} \cdot \mathrm{dm}^{-3}$. This resulted in the deterioration of the quality of the river and a risk of flooding. A good example of increased pollution in urban areas is the research by Ahn et al. [16]. According to the authors, the increase of water pollution in urban areas may be multifold as compared to the quality of natural waters. Field studies conducted for the Santa Ana River, which drains a large city gorge in Southern California, confirmed the increase of pollution in urban waters in relation to the natural ones, an example of which may be the amount of faecal bacteria in the river, which was $500 \%$ higher than in the water of the ocean baths.

Against this background, specific urban areas are those located in the zone of influence of the sea. This specificity is based on a constant wind from the sea (breeze), which increases air circulation dynamics and humidity. Consequently, this leads to possible increase in the number of rainy days, including extreme rainfall, and increased wash out of pollutants in urban areas [17]. It is very important, as the analysed watercourse (Orunski Stream) is in zone of direct impact of a marine basin, i.e. the Baltic Sea. Also important to the growth of pollution in the river may be the chemicals deposited in the sediments and released in case of weather changes bringing increased water flows [18]. Moreover, there is 
the phenomenon of re-suspension, which is related to wind conditions. What is important, some rivers flow through reservoirs, whose role in the accumulation of pollutants is visible. The examples include the studies for the Orunski Stream conducted by Pietruszynski et al. [19], who found that the periodic accumulation and deposition of biogenic compounds at the level of several to more than $300 \%$ of the load supplied to the reservoirs it possible. The consequence of this type of accumulation, possible in the case of the corresponding hydro-meteorological conditions (e.g. at the time of extreme events), is a rapid discharge of pollutants deposited in the river, thereby temporarily worsening its quality. As a result, apart from the increased concentration of specific chemical compounds, e.g. biogenic, there is also strong turbidity. It is especially visible in extreme situations, such as heavy rains and storms.

One of the main factors determining the growth of contamination of the water flowing into the receiver, which is a river, is the land use in the catchment [20]. Arable land as well as waste land and anthropogenic structures are the main sources of pollution of the river through leaching of chemical compounds. It increases during the rainfall periods, regardless of their intensity. According to Bindi and Olesen [21] to the intensification of agriculture may increase climate change, and therefore changes in weather conditions, shortages of water resources and qualitative changes. This aspect is important for Oruński Stream, because in the basin are considerable amounts of arable land. The quality of the river can also be affected by pollution from the atmosphere [22].

According to Zolch et al. [23] the volume of pollutants in a river basin is significantly correlated not only with the participation of developed land in the catchment area, but most of all with impermeable surfaces, which include residential buildings, roads, sidewalks and parking lots. According to Fraga et al. [24] understanding of the features of pollution on impervious surfaces is necessary to estimate properties of the pollution runoff from the city. The data obtained in studying them indicate that pollutants accumulated in the streets during dry periods are released quickly in times of rainfall and discharged into surface water receivers, but after a few days they slow down and get redistributed.

Finally, it must be said that it is important the factor of social acceptance in solving the problems related to water and its supply in urban areas [25]. The development of the city must take place in the aspect of sustainable development, so as to meet human needs, but not at the cost of environmental damage [26].

\section{Conclusions}

One of the objectives of this work was to study the catchment and watercourse response to extreme events. Examination of the water chemistry changes made two days before heavy rainfall showed a significant increase in sulphates and nitrogen compounds. Additionally, pollutants washed from the basin contributed to a significant deterioration in the water colour. What is also interesting are the results showing the reaction of the watercourse to extreme events. The rainfall of $1.3 \mathrm{~mm}$ caused an elevenfold increase of the flow, a twofold increase of the water level and a fourfold increase in the velocity of the water molecules. Moreover, there was than twofold increase in salinity, and conductivity of the water was also recorded during the rainfall. It might seem that such a small amount of rainfall has no significant effect on the hydrological and hydrochemical parameters. It turns out, however, that the maximum flow rates is an important variable when assessing the potential risks that can occur during hydrological threat in a small urban catchment due to 
flood. In addition, it can be seen that even small rainfall can significantly impact the change of the physico-chemical properties of water.

\section{References}

[1] McGrane SJ. Hydrological Sci J. 2016;61(13):2295-2311. DOI: 10.1080/02626667.2015.1128084

[2] Vetter T, Reinhardt J, Flörke M, van Griensven A, Hattermann F, Huang S, et al. Climatic Change. 2017;141:419. DOI: 10.1007/s10584-016-1794-y.

[3] Webber JL, Gibson MJ, Chen AS, Savic D, Fu G, Butler D. Urban Water J. 2018;15(3):210-217. DOI: 10.1080/1573062X.2018.1424212.

[4] Van Loon AF, Laaha G. J Hydrology. 2015;526:3-14. DOI: 10.1016/j.jhydrol.2014.10.059.

[5] Koop SHA, van Leeuwen CJ. Water Resources Manage. 2015;29:5649. DOI: 10.1007/s11269-015-1139-z.

[6] Ge Y, Wang XC, Dzakpasu M, Zheng Y, Zhao Y, Xiong J. Water Sci Technol. 2016;73 (11):2644-2653. DOI: $10.2166 /$ wst.2016.118.

[7] Angrill S, Petit-Boix A, Morales-Pinzón T, Josa A, Rieradevall J, Gabarrell X. J Environ Manage. 2017;189(15):14-21. DOI: 10.1016/j.jenvman.2016.12.027.

[8] Hoang L, Fenner RA. Urban Water J. 2016;13(7):739-758. DOI: 10.1080/1573062X.2015.1036083.

[9] Guan M, Sillanpää N, Koivusalo H. Hydrological Processes. 2015;29(13):2880-2894. DOI: 10.1002/hyp.10410.

[10] Redfern TW, Macdonald N, Kjeldsen TR, Miller JD, Reynard N. Progress Phys Geography: Earth Environ. 2016;40(5):699-713. DOI: 10.1177/0309133316652819.

[11] Majewski W. Meteorology Hydrol Water Manage Res Operational Applications. 2016;4(2):41-49. http://yadda.icm.edu.pl/yadda/element/bwmeta1.element.baztech-2787c16c-31b0-4b7b-9cf6-e5d279236968.

[12] Sakieh Y, Amiri BJ, Danekar A, Feghhi J, Dezhkam S. Environ Dev Sustain. 2015;17:1343. DOI: 10.1007/s10668-014-9609-7.

[13] Woodward G, Bonada N, Brown LE, Death RG, Durance I, Gray C, et al. Phil Trans R Soc B. 2016;371(1694):1-15. DOI: 10.1098/rstb.2015.0274.

[14] Miller T, Poleszczuk G. Ecol Chem Eng S. 2018;24(4):595-611. DOI: 10.1515/eces-2017-0039.

[15] Old GH, Leeks GJ, Packman JC, Smith BP, Lewis S, Hewitt EJ, et al. Sci Total Environ. 2003;314-316:495-512. DOI: 10.1016/S0048-9697(03)00070-6.

[16] Ahn JH, Grant SB, Surbeck SQ, DiGiacomo PM, Nezlin NP, Jiang S. Environ Sci Technol. 2005;39(16):5940-5953. DOI: 10.1021/es0501464.

[17] Costa A, Schaider L, Hughes P. Green Chem. 2018;317-337. DOI: 10.1016/B978-0-12-809270-5.00013-3.

[18] Ockenden MC, Deasy CE, Benskin CWH, Beven KJ, Burke S, Collins AL, et al. Sci Total Environ. 2016;548-549:325-339. DOI: 10.1016/j.scitotenv.2015.12.086.

[19] Pietruszyński Ł, Olszewska A, Bogdanowicz R. Limnolog Rev. 2012;12(2):87-92. DOI: 10.2478/v10194-011-0048-7.

[20] Rogger M, Agnoletti M, Alaoui A, Bathurst JC, Bodner G, Borga M. Water Resour Res. 2017;53(7):5209-5219. DOI: 10.1002/2017WR02072.

[21] Bindi M, Olesen JE. Regional Environ Change. 2011;11(1):151-158. DOI: 10.1007/s10113-010-0173-x.

[22] Cichowicz R, Wielgosiński G. Ecol Chem Eng S. 2018;25(2):217-227. DOI: 10.1515/eces-2018-0014.

[23] Zölch T, Henze L, Keilholz P, Pauleit S. Environ Res. 2017;157:135-144. DOI: 10.1016/j.envres.2017.05.023.

[24] Fraga I, Charters FJ, O'Sullivan AD, Cochrane TA. J Environ Manage. 2016;167:75-84. DOI: 10.1016/j.jenvman.2015.11.003.

[25] Mees H, Crabbé A, Driessen PPJ. J Environ Policy Planning. 2017;19(6):827-842. DOI: 10.1080/1523908X.2017.1299623.

[26] Kroto HW, Zielińska M, Rajfur M, Wacławek M. Chem Didact Ecol Metrol. 2016;21(1-2):11-27. DOI: 10.1515/cdem-2016-0001. 